\title{
Microbial ecology and effectiveness of different starter cultures in yoghurts produced from whole cow milk and soybeans
}

\author{
Charles Bristone, ${ }^{1,2}$ Ernest Chukwusoro Igwe, ${ }^{1,3}$ Mamudu H. Badau, ${ }^{2^{\star}}$ Ohene Boafo, ${ }^{1}$ Vincent \\ Glaku Zira'
}

\author{
${ }^{1}$ Modibbo Adama University of Technology, Yola, Department of Food Science and Technology, P.M.B. 2076. Yola, \\ Adamawa state, Nigeria \\ ${ }^{2}$ University of Maiduguri, Faculty of Engineering, Department of Food Science and Technology, P.M.B. 1069, Maiduguri, \\ Borno State, Nigeria \\ ${ }^{3}$ Nnamdi Azikiwe University, Department of Food Science and Technology, P.M.B. 2076. Akwa, Anambara State, \\ Nigeria \\ *Corresponding Author: Email; mamudu_badau@yahoo.com, mamudubadau@gmail.com, Tel.: +2348064191868
}

\section{ABSTRACT}

\begin{abstract}
The microbial ecology and acceptability of milks and yoghurts produced from whole cow milk and soybeans were carried out. This was done to determine the acceptability of milks and yoghurts upon post fermentation at room temperature $\left(31 \pm 2{ }^{\circ} \mathrm{C}\right)$. Thr ee different starter cultures from different sources were inoculated on whole cow milk (100\%), whole soymilk $(100 \%)$ and cow-soymilk composite $(1: 1)$. While other whole cow milk (100\%) and whole soymilk (100\%) were left without inoculation. They were all fermented for 6, 24 and 48 hours. Their pH, titrable acidity, microbiological properties and sensory attributes were evaluated. Sensory attributes of fresh milks showed no significant $(p>0.05)$ difference. However, there was significant $(p<0.05)$ variation for all set of yoghurts and at 48 hours they were disliked extremely. $\mathrm{pH}$ of milks ranged from $5.80-6.80$, titrable acidity $0.02-0.06 \%$, total plate count 1.5 $\times 10^{5}-21.07 \times 10^{5} \mathrm{cfu} / \mathrm{ml}$ from 0 to 24 hours fermentation. While pH of yoghurts also ranged from $3.30-$ 6.90 , titrable acidity $0.04-1.09 \%$, total plate count $0.0 \times 10^{5}-51.76 \times 10^{6} \mathrm{cfu} / \mathrm{ml}$ from 0 (i.e. 6 hours) to 48 hours fermentation times. The microbial ecology of interactions with milks and yoghurts are Streptococcus sp, Lactobacillus sp, Micrococcus sp, Bacillus sp, Staphylococcus aureus, Mucor sp, and Yeast cells. Good sensory attributes were observed at 0 (i.e 6) hours for milks and at 6 and 24 hours for yoghurts. Yoghurt samples with formulations cow milk fermented with commercial starter were found slightly more acceptable followed by the ones fermented with indigenous starter (Kindirmo) and lastly Nagge yoghurt.
\end{abstract}

Keywords: Fermentation, Sensory attributes, Titrable acidity, Acceptable, Indigenous.

\section{INTRODUCTION}

In developing countries like Nigeria, there is high demand for fermented milk and milk products especially those of plants origin. People are becoming more enlightened on the benefits of consuming plants and animals fermented dairy products (Udeozor and Awonorin, 2014, Bibiana et al., 2014; Bristone et al., 2015). Consumption of fermented milk such as yoghurt containing lactic acid bacteria have been reported to reduce intestinal toxin and cancer causing bacteria, virgina infections, blood pressure and osteoporosis (Farnworth et al., 2007; Farinde et al., 2008; Shahnawaz et al., 2013; Bibiana et al., 2014). Yoghurt is known for its therapeutic properties and health maintenance (Ismael et al., 2014). Research evidence found out that some countries where fermented dairy products are dietary staple foods add years to life (Amanze and Amanze, 2011).

On the other hand, starter cultures of lactic acid bacteria have been known to ferment or colonise diverse food and inhibit the growth of other microorganisms (Sudi et al., 2014). These brought about "the study of reciprocal relations between microorganisms and their environment" (whether immediate or external) which is known as the 
108 Afr. J. Food Sci. Technol.

microbial ecology (Dubey and Maheshwari, 2014). Microbial interaction with milk or fermented milk leading to succession or spoilage was described by Ray (2001). Similarly, mutually favourable interactions which are not completely interdependent between Lactobacillus sp and Streptococcus thermophillus have been known to be proto-corporation (Sukumar, 2002). These form the basis of their ability to improve the keeping quality and safety of many food products (Sudi et al., 2011). Researchers reported that milk fermentation by lactic acid bacteria is a way of preservation. Similarly, it is one of the approaches to prolong the shelf life of food products (Akoma et al., 2000; Akpan et al., 2007; Amanze and Amanze, 2011; Shahnawaz et al., 2013).

The products of lactic acid fermentation of milk were reported to be diverse. These includes: simple sugars, hydrogen peroxide, ethanol, bactericidal peptides, organic and amino acids with varying biological actions such as angiotensin-converting enzymes (ACE) inhibitor, immune modulator and antioxidant activities (Sukumar, 2002; Ismael et al., 2014).

Furthermore, industries have been reported to improve production method for product diversity. In this case, starter cultures are used to ferment milk for a specific period and desired flavours are achieved (Bristone et al., 2015). Fermentation by lactic acid bacteria were known to create variety, improve the nutritional value as well as enhance the acceptability of the products (Akoma et al., 2000). It was also reported that the flavour and texture of yoghurt vary depending on the country of origin as well as other factors including raw materials formulation and production process (Bibiana et al., 2014). Similar case was also reported by Bristone et al. (2015). Besides these, proper selection and balance for starter cultures were reported as critical for the production of fermented products of desired texture and flavour using industrial starters. However, consumers were reported to prefer traditional fermented milks (Wakil et al., 2014). It is for these reasons, that sometimes ingredients such as whole foods, juice, jams, herbs, spices, thickeners and sweeteners are being added to improve quality of yoghurts (Akpan et al., 2007; Wakil et al., 2014; Bristone et al., 2015).

To achieve these desires, the effectiveness of starter culture(s) is the key element. It must yield the intended result. In facts, it must dominate over naturally occurring microflora and produce the desired end products of fermentation. Besides, bacteriophage resistance, genetic stability, safety, economic values, easy to reproduce and rapid growth rate or performance are other requirements (Mullan, 2001; Farnworth et al., 2006; Yao, et al., 2009; Wakil et al., 2014). The uses of commercial starter culture have recorded a successful history in yoghurt production. However, indigenous starter culture such as kindirmo is less explored (Farinde et al., 2008; Amanze and Amanze, 2011; Sudi et al., 2011; Ismaila et al., 2011; Wakil et al., 2014).
Health benefits of milk produced from plant sources were reviewed by Sowonola et al. (2005), Bamishaiye and Bamishaiye (2011) and Gambo and Da'u (2014). Milk extract from tiger nut, soybeans and bambara nut were extensively investigated and results were much comparable to cow milk especially soybeans milk extract (Udeozor, 2012; Udeozor and Awonorin, 2014; Adedokun et al., 2014; Udeze et al., 2014; Odu and Egbo, 2012; Ukwuru and Ogbodo, 2012; Musa and Hamza, 2013; Bristone et al., 2015). However, yoghurts produced from these sources never yield same quality as cow milk yoghurt, even if supplemented with cow milk (Farinde et al., 2008; Amanze and Amanze, 2011; Bristone et al., 2015). One of the critical area reported which affect fermentation of milk extract from plants sources such as soymilk is due to biotransformation level of the non-active Isoflavone Glycosides (IG) in soybeans to biologically active forms is low (Isoflavone Aglycones i.e. IA) by microorganism such as Bifidobacteria and Lactobacillus (Pham and Shah, 2009).

Yoghurt produced from cow milk and soybean milk, have been investigated by many researchers. Akpan et al. (2007) studied effect of preservatives on the shelf life of yoghurt produced from soybean milk. The study aim was achieved within 21 days storage. Similar study by Olorunnisomo et al. (2014) on homogenization of milk and its effect on sensory and physicochemical properties of yoghurt produced from cow milk indicated good storage stability from 0 to 10 days refrigeration. Physicochemical analysis of desi yoghurt produced by the local community in Gilgit District in Pakistan was also examined (Shahnawaz et al., 2013). Other study related to proximate composition include: quality evaluation of yoghurt from cow milk, soymilk and cow/soymilk (Amanze and Amanze, 2011) and also production and evaluation of yoghurt from mixtures of cow milk, milk extract from soybeans and tiger nut (Bristone et al., 2015). Microbial issues on yoghurt production also have been investigated by Farnworth et al. (2007), Farinde et al. (2008) and Ismaila et al. (2011). Results obtained are absolutely impressive for scientific advancement.

Nevertheless, the indigenous breed expected to supply the needed milk for the teaming population cannot meet the demand of people. The dry powdered milk which is used as substitute for the insufficient indigenous milk supply is mostly imported which drains our foreign exchange earnings. The commercial starter cultures are also imported and are not much available (Farinde et al., 2008; Amanze and Amaze, 2011; Udeozor, 2012; Wakil et al., 2014; Bibiana et al., 2014; Bristone et al., 2015). Therefore, the annual deficit usually encountered in milk supply can be replenished by milk from plant sources such as soymilk. The use of indigenous starter culture and also supplementation of soymilk by cow milk cannot be overemphasized. Fermentation of these mixtures at different times would aid biotransformation, create variety; enhance product acceptability and knowledge of 
various interactions. The objectives of this study were to examine the microbial ecology and acceptability of milks and yoghurts at different fermentation times in relation to starter cultures.

\section{MATERIALS AND METHODS}

\section{Source of material}

Fresh raw milk and Kindirmo (indigenous mix starter culture) were supplied by a local farmer from Sangere, within Girei Local Government Area. Soybean was procured from Jimeta main market. Fresh Nagge yoghurt (starter culture) was obtained from Nagge factory in Jimeta. Commercial starter culture (BIO BIF, Malaysia) was procured from the distributors from Lagos.

\section{Production of soymilk}

Soybean was hand-sorted to remove contaminant and fines. A portion of $1.6 \mathrm{~kg}$ was weighed and soaked for five hours in a clean water of three times its weight by volume until the coat became soaked and wet to assist in removal of soluble anti-nutrients and to enhance dehulling. Soybeans were further rinsed, drained and partially sun-dried. After that, it was toasted at surface temperature of $180 \pm 3^{\circ} \mathrm{C}$ for 30 minutes in thick aluminium pot (Ory, 1986; Salunkhe et al., 1992; Iwe, 2003; Badau et al., 2005, 2006). Dehulling was done by cracking using grinding machine and was manually winnowed and weighed $(1.4 \mathrm{~kg})$. This was ground to powder by hammer mill (Foxhills Ind. EST Scunthorpe, DE DN15 8QW, England) and let to pass through $0.8 \mathrm{~mm}$ mesh sieve which yielded $1.2 \mathrm{~kg}$ powder flour. A $0.5 \mathrm{~kg}$ part of the $1.2 \mathrm{~kg}$ was reconstituted with 3 litres of clean water and was strained through muslin cloth to obtain soymilk.

\section{Production of yoghurts}

Three different prepared starter cultures (kindirmo, Nagge yoghurt and commercial starter) were used for the production of yoghurts from soymilk $(100 \%)$, cow milk $(100 \%)$ and soymilk- cow milk composite (1:1).

Fresh milks were pasteurized at $90^{\circ} \mathrm{C}$ for 15 min utes. They were allowed to cool to $41^{\circ} \mathrm{C}$ and each was inoculated with $2 \%$ starter culture. All were allowed to ferment for 6 hours (Sukumar, 2002; Bristone et al., 2015) at room temperature $\left(31 \pm 2^{\circ} \mathrm{C}\right)$ which yielded fi rst set of yoghurts (first phase of yoghurts). The experiment was repeated using "back-sloping" (Mullan, 2001).

\section{Experimental design}

To fully attain the research objective of this study, two experiments were conducted as follows: first set of experiment on cow milk (100\%) and soymilk (100\%). They are analysed at day I ( 6 hours) and day II (24 hours). Second set of experiment (in two phases) on yoghurts produced from those milks mentioned above, using three different starter cultures at different fermentation time. A $2(3 \times 3 \times 1 \times 3)$ factorial in a completely randomized design was used as described by Gomez and Gomez (1983). However, twelve (12) out of these formulations containing soymilk inoculated with kindirmo, Nagge yoghurt, self processed kindirmo and self processed Nagge yoghurt starter culture were screened out during preliminary studies. The $\mathrm{pH}$, titrable acidity, microbiological properties and sensory attributes of milks and yoghurts were evaluated at 0 (i.e. 6), 24 and 48 hours (day III) fermentation time until products were extremely discriminated by panellists.

\section{pH measurement}

The $\mathrm{pH}$ of the test sample was measured using digital $\mathrm{pH}$ metre (Equip-Tronics, EQ-610, Mumbai). After calibration with standard buffers of $\mathrm{pH} 4,7$ and $14,5 \mathrm{ml}$ of each of the samples was mixed thoroughly with $15 \mathrm{ml}$ of distilled water in a beaker. The probe of the $\mathrm{pH}$ metre was inserted and the $\mathrm{pH}$ value was read and recorded keeping in mind to rinse probe properly for subsequent use on next sample (Blanco and Sherbo, 1978; AOAC, 1990; Shahnawaz et al., 2013; Igbadul et al., 2014; Olorunnisomo et al., 2014).

\section{Determination of titrable acidity}

The titrable acidity of sample was measured using $10 \mathrm{ml}$ of weighed sample into conical flask and 3 drops of phenolphthalein indicator was added and titrated with $0.1 \mathrm{~m}$ of sodium hydroxide $(\mathrm{NaOH})$ until a pink colour appeared. The titre value was recorded and was expressed as percentage lactic acid (Egan et al., 1988; AOAC, 1990; Shahnawaz et al., 2013; Igbadul et al., 2014; Olurunnisomo et al., 2014).

$$
\begin{aligned}
& \text { Percentage lactic acid }=\frac{\text { titre value } \mathrm{x} \text { lactic acid factor }}{10 \mathrm{ml} \text { of sample }} \\
& \text { Microbiological analysis }
\end{aligned}
$$

Preparation of glass wares and media; glass wares were oven sterilized by dry heat (Medified Equipment and Scientific DHG-9023A, England) at $160^{\circ} \mathrm{C}$ for 60 minu tes as described by Fawole (1988) and Cheesbrough (2000). Each microbial medium was prepared as follows: $28 \mathrm{~g}$ of nutrient agar (BDH Chemicals Ltd, 28304, poole England), $48.5 \mathrm{~g}$ of MacConkey agar (Scharlauchemie S. A. 01-111, Barcelona, Spain), $39 \mathrm{~g}$ of Potato dextrose 
110 Afr. J. Food Sci. Technol.

Table 1. pH, titrable acidity and total plate count of cow milk and soymilk

\begin{tabular}{lllll}
\hline Samples & Cow milk & & Cow milk & \\
\hline Ph & $6.80 \pm 0.00^{\mathrm{a}}$ & $6.30 \pm 0.10^{\mathrm{b}}$ & $6.70 \pm 0.00^{\mathrm{a}}$ & Soymilk $_{2}$ \\
Titrable Acidity $(\%)$ & $0.02 \pm 0.00^{\mathrm{b}}$ & $0.06 \pm 0.01^{\mathrm{a}}$ & $0.02 \pm 0.00^{\mathrm{b}}$ & $0.05 \pm 0.00^{\mathrm{a}}$ \\
Total plate count $(\mathrm{cfu} / \mathrm{ml})$ & $1.5 \times 10^{5}$ & $10.6 \times 10^{5}$ & $12.3 \times 10^{5}$ & $21.07 \times 10^{5}$ \\
\hline
\end{tabular}

Each value is a mean $\pm S D$ of triplicate determinations. Mean values in a row not sharing a common superscript letters are significantly $(p<0.05)$ different.

Note: 1 = day I, 2 = day II

agar (lifesave Biotech, Trade St. San Diego (CA92121, USA), $57.5 \mathrm{~g}$ Kligler iron agar (BDA Chemicals Ltd., 28304 Poole England), $24 \mathrm{~g}$ of Simmon's citrate agar (BDH chemicals Ltd., 28304 Poole England) $15 \mathrm{~g}$ of peptone water (Oxoid Itd., Basingstoke Hants, England) into $1000 \mathrm{ml}$ (1 litre) of distilled water each as described by the manufacturers. Each was dissolved and autoclaved at $121^{\circ} \mathrm{C}$ for 15 minutes (Fawole, 1988; Cheesbrough, 2000; Jideani and Jideani, 2006). Isolates identified during this study were at power five dilutions.

\section{Serial dilution}

A prepared $1 \mathrm{ml}$ of sample was transferred into bijou bottle containing $9 \mathrm{ml}$ of sterilized distilled water to form stock solution. Then from the stock solution, $1 \mathrm{ml}$ was also transferred into subsequent bottle containing $9 \mathrm{ml}$ sterilized distilled water until required serial dilution was made (Diliello, 1982; Jideani and Jideani, 2006; Igbadul et al., 2014).

\section{Total plate count}

From the stock solution, $1 \mathrm{ml}$ was transferred aseptically into sterilized labelled plate (pour plate method). About 15 to $18 \mathrm{ml}$ of cooled nutrient agar was added, swirled and was allowed to solidify before incubating at $35^{\circ} \mathrm{C}$ for 24 hours (Harigan and McCance, 1979; Diliello, 1982; Jideani and Jideani, 2006). The numbers of microorganisms were obtained using:

Colony forming unit $(\mathrm{cfu} / \mathrm{ml})=\frac{\text { number of colonies }}{\text { volume transferred to plate } \mathrm{x} \text { dilution blank factor }}$

\section{Microbiological characterization and identification}

Cultural characteristics of bacterial isolates were examined after 24 hours incubation. Morphological characteristics of bacterial isolates were observed microscopically (Olympus Optical Co. Ltd., CHA and $\mathrm{CHB}$, Japan). The biochemical test conducted include: catalase, oxidase, indole, coagulase, citrate, hydrogen sulphide production and carbohydrate utilization test as described by Singleton (1999), Cheesbrough (2000) and Jideani and Jideani (2006). However, some of them were used to ensure that Gram - type reaction were not faulted. For the fungal isolates, the cultures were grown on potato dextrose agar (containing $10 \%$ tartaric acid) at room temperature and were observed daily for 14 days for cultural characteristics and for proper development of spores. Later, the isolates were stained with lactophenol cotton blue stain and were observed microscopically for morphological characteristics and for identification (Harigan and McCance, 1979; Fawole, 1988; Cheesbrough, 2000).

\section{Sensory evaluation}

Ten taste panellists who were familiar with yoghurts and milks were selected from among the lecturers and students of the Department of Food Science and Technology. They were served with the test samples in a white transparent take-away plastic cups and spoons. They were also reminded to rinse their mouth with fresh sachet water before tasting next sample. The containers containing the samples were coded with three digit random number. Panellists were asked to rank the samples on the basis of their quality attributes (consistency, flavour, taste, colour, texture and overall acceptance) using nine-point hedonic scale, expressing degree of liking or disliking as in the questionnaire (Larmond, 1977; Badau et al., 2006; Igbadul et al., 2014). Note samples were without sugar.

\section{Statistical analysis}

Where appropriate, means and ranges of values were separated by Duncan's multiple range test (Duncan, 1955).

\section{RESULTS}

The $\mathrm{pH}$, titrable acidity and total plate count of cow milk and soymilk are presented in Table 1 . The $\mathrm{pH}$ values ranged from $6.70-6.80$ (day 1), $5.80-6.30$ (day II) and these correspond to titrable acidity of $0.02 \%$ (no range), $0.05-0.06$ and also total plate count of $1.5 \times 10^{5}-12.3 \times$ $10^{5} \mathrm{cfu} / \mathrm{ml}$ and $10.6 \times 10^{5}-21.07 \times 10^{5} \mathrm{cfu} / \mathrm{ml}$ respectively. At day II there was much $\mathrm{pH}$ reduction for both milks. Soymilk has much more reduction and high 
Table 2. Distribution of microorganisms in cow milk and soymilk

\begin{tabular}{llll}
\hline Samples & Streptococcus sp & Micrococcus sp & Yeast \\
\hline Cow milk & $+(4)$ & $+(7)$ & $-(0)$ \\
Soymilk $_{1}$ & $+(97)$ & $+(23)$ & $+(3)$ \\
Cow milk & $+(82)$ & $+(24)$ & $-(0)$ \\
Soymilk & $+(2066)$ & $+(36)$ & $+(5)$ \\
Total & $2249(95.74 \%)$ & $90(3.83 \%)$ & $10(0.43 \%)$ \\
\hline
\end{tabular}

Note: 1 = day I,

2 = day II, += positive, - = negative

.Table 3. Sensory scores of cow milk and soymilk

\begin{tabular}{|c|c|c|c|c|c|c|}
\hline Sample & Sensory factc & & & & & \\
\hline & Consistency & Flavour & Taste & Colour & texture & $\begin{array}{l}\text { Overall } \\
\text { acceptance }\end{array}$ \\
\hline $\mathrm{Cm}_{1}$ & $7.60 \pm 2.32^{\mathrm{a}}$ & $8.30 \pm 0.4^{a}$ & $8.70 \pm 0.48^{a}$ & $9.0 \pm 0.0^{a}$ & $8.30 \pm 0.67^{\mathrm{a}}$ & $8.60 \pm 0.52^{\mathrm{a}}$ \\
\hline $\mathrm{Sm}_{1}$ & $7.40 \pm 2.22^{\mathrm{a}}$ & $7.10 \pm 2.51^{a}$ & $7.70 \pm 1.49^{\mathrm{a}}$ & $5.80 \pm 2.97^{\mathrm{ab}}$ & $6.70 \pm 2.16^{\mathrm{ab}}$ & $7.40 \pm 2.22^{\mathrm{a}}$ \\
\hline $\mathrm{Cm}_{2}$ & $5.20 \pm 3.12^{\mathrm{ab}}$ & $7.70 \pm 0.95^{\mathrm{a}}$ & $4.50 \pm 3.14^{\mathrm{b}}$ & $6.30 \pm 3.40^{\mathrm{ab}}$ & $4.10 \pm 2.73^{\mathrm{bc}}$ & $6.00 \pm 2.87^{\mathrm{ab}}$ \\
\hline $\mathrm{Sm}_{2}$ & $3.70 \pm 2.87^{\mathrm{b}}$ & $2.80 \pm 1.93^{\mathrm{b}}$ & $1.80 \pm 1.23^{\mathrm{c}}$ & $4.70 \pm 3.47^{\mathrm{b}}$ & $3.00 \pm 2.83^{\mathrm{c}}$ & $4.10 \pm 3.07^{\mathrm{b}}$ \\
\hline
\end{tabular}

Each value is a mean \pm SD of triplicate determinations. Mean values in a column not sharing a common superscript letters are significantly $(\mathrm{p}<0.05)$ different.

Note: $\mathrm{Cm}=$ Cow milk, $\mathrm{Sm}=$ Soymilk, 1 = Day I, 2 = Day II.

total plate count for both days. It can also be inferred from same table that the total microorganism increases upon incubation. This means that as the total microorganism of the two samples increases, activities also increases which resulted in the increase in their titrable acidity. These changes are an indication of spoilage from standard point of view.

Table 2 indicated distribution of microorganisms in cow milk and soymilk. The microorganism at day I and II are Streptococcus sp 2,249 (95.74\%), Micrococcus sp 90 $(3.83 \%)$ and yeast $10(0.43 \%)$. The difference is that no yeast was observed in cow milk. Micrococcus $s p$ dominate both milks at day I. However, at day II it was Streptococcus sp, with rapid growth rate.

Table 3 showed sensory scores of cow milk and soymilk. No significant $(p>0.05)$ difference at day I and cow milk was rated high for colour. All sensory attributes at day I for both milk exhibited high level of acceptability by panellists. At day II all the quality attributes for both milks dropped significantly. Sensory attributes for soymilk falls below the established baseline statistics of neither liked nor disliked (5). Taste for soymilk has the lowest rating as compared to all the sensory attributes for both milks. Lowest level (i.e. 1) among range of values was observed in soymilk. Generally, the sensory scores related directly to the result of Table 1 and 2 .

Table 4 showed $\mathrm{pH}$, titrable acidity and total plate count of yoghurts of the first phase. At day I the $\mathrm{pH}$ values range from $4.20-6.90$, day II from $3.30-5.30$, day III from $3.40-5.00$ and these correspond to titrable acidity of $0.04-0.09 \%, 0.05-1.09 \%, 0.05-1.09 \%$ and also total plate count from $0.2 \times 10^{5}-36.9 \times 10^{5} \mathrm{cfu} / \mathrm{ml}$, $0.0 \times 10^{5}-36.1 \times 10^{5}$ and $2.7 \times 10^{5}-51.76 \times 10^{6} \mathrm{cfu} / \mathrm{ml}$ respectively.

Table 5 showed the distribution of microorganisms in yoghurts of the first phase. Microorganisms isolated are Streptococcus sp 13,878 (96.15\%), Micrococcus $s p$ 472(3.27\%), Lactobacillus sp $43 \quad(0.30 \%)$, Staphylococcus aureus 4 (0.03\%), Mucor sp 14 (0.10\%) and un-identified group of yeast cells $9(0.06 \%)$. Day III has the highest percentage microorganisms. Yeasts and Mucor sp were observed at day II and III and were found mostly associated with yoghurts produced from cowsoymilk (1:1) and soymilk (100\%). Streptococcus sp and Micrococcus $s p$ were found to dominate groups of yoghurts produced.

Table 6 showed sensory scores of yoghurts of the first phase. There was significant $(p<0.05)$ difference in their sensory attributes. However, flavours of yoghurts showed no variation $(p>0.05)$. It was mostly observed that if the sensory attributes of the yoghurts were rated low the first day then the subsequent day's rating of yoghurts will be high. But if it were the first day then the following day will be low. Cow milk fermented with commercial starter and indigenous starter culture were observed more acceptable. The composite yogurts usually rated low. Ratings for all the yoghurt dropped significantly at day III (indicating low level of acceptability). 
112 Afr. J. Food Sci. Technol.

Table 4. $\mathrm{pH}$, titrable acidity and total plate count of yoghurt of the first phase

\begin{tabular}{|c|c|c|c|}
\hline Sample code & $\mathrm{pH}$ & Titrable acidity (\%) & Total plate count (CFU/ml) \\
\hline $\mathrm{CMFMK}_{1}$ & $4.20 \pm 0.00^{\circ \mathrm{P}}$ & $0.09 \pm 0.01^{\mathrm{C}}$ & $12.5 \times 10^{5}$ \\
\hline $\mathrm{CMFMN}_{1}$ & $6.10 \pm 0.00^{b}$ & $0.05 \pm 0.00^{d}$ & $0.2 \times 10^{5}$ \\
\hline $\mathrm{CMFCO}_{1}$ & $4.90 \pm 0.00^{\mathrm{hi}}$ & $0.09 \pm 0.01^{c}$ & $8.2 \times 10^{5}$ \\
\hline CSMFMK $_{1}$ & $4.40 \pm 0.00^{\mathrm{mn}}$ & $0.09 \pm 0.01^{\mathrm{c}}$ & $1.0 \times 10^{5}$ \\
\hline CSMFMN $_{1}$ & $5.10 \pm 0.00^{\text {fg }}$ & $0.05 \pm 0.01^{d}$ & $5.5 \times 10^{5}$ \\
\hline $\mathrm{CSMFCO}_{1}$ & $5.2 \pm 0.00^{\mathrm{et}}$ & $0.05 \pm 0.01^{d}$ & $2.8 \times 10^{5}$ \\
\hline WSMFMCO $_{1}$ & $5.20 \pm 0.00^{\text {ef }}$ & $0.09 \pm 0.01^{\mathrm{c}}$ & $36.9 \times 10^{5}$ \\
\hline $\mathrm{CMFMK}_{2}$ & $3.90 \pm 0.10^{r}$ & $1.09 \pm 0.00^{\mathrm{a}}$ & $17.7 \times 10^{5}$ \\
\hline $\mathrm{CMFMN}_{2}$ & $3.40 \pm 0.00^{\mathrm{s}}$ & $1.08 \pm 0.00^{\mathrm{a}}$ & $6.1 \times 10^{5}$ \\
\hline $\mathrm{CMFCO}_{2}$ & $4.40 \pm 0.00^{\mathrm{mn}}$ & $0.09 \pm 0.01^{c}$ & $13.3 \times 10^{5}$ \\
\hline CSMFMK $_{2}$ & $4.10 \pm 0.00^{\mathrm{pq}}$ & $0.09 \pm 0.01^{\mathrm{c}}$ & $6.9 \times 10^{5}$ \\
\hline $\mathrm{CSMFMN}_{2}$ & $4.20 \pm 0.00^{\circ p}$ & $0.09 \pm 0.01^{c}$ & $17.8 \times 10^{5}$ \\
\hline $\mathrm{CSMFCO}_{2}$ & $4.5 \pm 0.00^{\prime m}$ & $0.09 \pm 0.00^{\mathrm{c}}$ & $6.9 \times 10^{5}$ \\
\hline WSMFMCO $_{2}$ & $5.20 \pm 0.00^{\text {ef }}$ & $0.05 \pm 0.01^{\mathrm{d}}$ & $51.1 \times 10^{5}$ \\
\hline $\mathrm{CMFMK}_{3}$ & $3.90 \pm 0.10^{r}$ & $1.09 \pm 0.00^{\mathrm{a}}$ & $71.9 \times 10^{5}$ \\
\hline $\mathrm{CMFMN}_{3}$ & $4.20 \pm 0.00^{\circ \mathrm{p}}$ & $0.09 \pm 0.02^{c}$ & $2.7 \times 10^{5}$ \\
\hline $\mathrm{CMFCO}_{3}$ & $4.00 \pm 0.00^{\text {qr }}$ & $0.09 \pm 0.01^{c}$ & $23.15 \times 10^{6}$ \\
\hline $\mathrm{CSMFMK}_{3}$ & $4.90 \pm 0.01^{\mathrm{hi}}$ & $0.09 \pm 0.01^{\mathrm{c}}$ & $26.30 \times 10^{6}$ \\
\hline $\mathrm{CSMFMN}_{3}$ & $4.30 \pm 0.00^{\text {no }}$ & $0.09 \pm 0.01^{c}$ & $51.76 \times 10^{6}$ \\
\hline $\mathrm{CSMFCO}_{3}$ & $4.5 \pm 0.00^{\mathrm{Im}}$ & $0.09 \pm 0.00^{c}$ & $77.0 \times 10^{5}$ \\
\hline $\mathrm{WSMFMCO}_{3}$ & $5.00 \pm 0.00^{g h}$ & $0.05 \pm 0.00^{d}$ & $90.7 \times 10^{5}$ \\
\hline
\end{tabular}

Each value is a mean \pm SD of triplicate determinations. Mean values in a column not sharing a common superscript letters are significantly $(p<0.05)$ different.

Note: CMFMK=Cow milk fermented with kindirmo, CMFMN=Cow milk fermented with Nagge, CMFCO=Cow milk fermented with commercial starter culture, CSMFMK=Cow-soymilk fermented with kindirmo, CSMFMN=Cow-soymilk fermented with Nagge, CSMFCO=Cow-soymilk fermented with commercial starter culture, WSMFMCO=whole soymilk fermented with commercial starter culture. 1, 2, 3 = day I, II, and III respectively.

Table 5 .Distribution of microorganisms in yoghurt of the first phase

\begin{tabular}{|c|c|c|c|c|c|c|c|c|}
\hline Samples Code & & $\begin{array}{l}\text { Streptococcus } \\
\text { sp }\end{array}$ & Micrococcus sp & Bacillus $s p$ & Lactobacillus sp & $\begin{array}{l}\text { Staphylococcus } \\
\text { aureus }\end{array}$ & Yeast cell & Mucor sp \\
\hline CMFMK $_{1}$ & & $+(121)$ & $+(4)$ & $-(0)$ & $-(0)$ & $-(0)$ & $-(0)$ & $-(0)$ \\
\hline $\mathrm{CMFMN}_{1}$ & & $+(1)$ & $+(1)$ & $-(0)$ & - & $+(1)$ & $-(0)$ & $-(0)$ \\
\hline $\mathrm{CMFMCO}_{1}$ & & $+(74)$ & $+(3)$ & $-(0)$ & $+(5)$ & $-(0)$ & $-(0)$ & $-(0)$ \\
\hline CSMFMK $_{1}$ & & $+(7)$ & $+(2)$ & $-(0)$ & $-(0)$ & $+(1)$ & $-(0)$ & $-(0)$ \\
\hline CSMFMN $_{1}$ & & $+(46)$ & $+(9)$ & $-(0)$ & -(0) & $-(0)$ & $-(0)$ & $-(0)$ \\
\hline CSMFMCO $_{1}$ & & $+(44)$ & $+(2)$ & $-(0)$ & $-(0)$ & $+(2)$ & $-(0)$ & $-(0)$ \\
\hline WSMFMCO $_{1}$ & & $+(301)$ & $+(68)$ & $-(0)$ & $-(0)$ & $-(0)$ & $-(0)$ & $-(0)$ \\
\hline $\mathrm{CMFMK}_{2}$ & & $+(171)$ & $+(6)$ & -(0) & - & $-(0)$ & - & $-(0)$ \\
\hline $\mathrm{CMFMN}_{2}$ & & $+(50)$ & $+(11)$ & $-(0)$ & $-(0)$ & $-(0)$ & $-(0)$ & - \\
\hline $\mathrm{CMFMCO}_{2}$ & & $+(125)$ & $+(5)$ & $-(0)$ & $+(3)$ & - & - & $-(0)$ \\
\hline CSMFMK $_{2}$ & & $+(63)$ & $+(3)$ & $-(0)$ & $-(0)$ & $-(0)$ & $+(1)$ & $+(2)$ \\
\hline $\mathrm{CSMFMN}_{2}$ & & $+(172)$ & $+(4)$ & $-(0)$ & - & $-(0)$ & $+(2)$ & $-(0)$ \\
\hline $\mathrm{CSMFMCO}_{2}$ & & $+(66)$ & $+(2)$ & $-(0)$ & $-(0)$ & $-(0)$ & $-(0)$ & $+(1)$ \\
\hline $\mathrm{WSMFMCO}_{2}$ & & $+(504)$ & $+(4)$ & $-(0)$ & - & $-(0)$ & $+(1)$ & $+(2)$ \\
\hline $\mathrm{CMFMK}_{3}$ & & $+(703)$ & $+(16)$ & $-(0)$ & $-(0)$ & $-(0)$ & $-(0)$ & $-(0)$ \\
\hline $\mathrm{CMFMN}_{3}$ & & $+(24)$ & $+(3)$ & $-(0)$ & - (0) & $-(0)$ & - & $-(0)$ \\
\hline $\mathrm{CMFMCO}_{3}$ & & $+(2220)$ & $+(44)$ & $+(14)$ & $+(35)$ & $-(0)$ & $+(2)$ & - \\
\hline $\mathrm{CSMFMK}_{3}$ & & $+(2528)$ & $+(97)$ & $-(0)$ & $-(0)$ & $-(0)$ & $+(2)$ & $+(3)$ \\
\hline $\mathrm{CSMFMN}_{3}$ & & $+(5074)$ & $+(102)$ & $-(0)$ & -(0) & - & $-(0)$ & $-(0)$ \\
\hline $\mathrm{CSMFMCO}_{3}$ & & $+(727)$ & $+(39)$ & $-(0)$ & -(0) & $-(0)$ & $-(0)$ & $+(4)$ \\
\hline WSMFMCO $_{3}$ & & $+(857)$ & $+(47)$ & - & -(0) & - & $+(1)$ & $+(2)$ \\
\hline $\begin{array}{l}\text { TOTAL } \\
\text { PERCFNAGF }\end{array}$ & $\&$ & 13878 (96.15\%) & 472 (3.27\%) & $14(0.10 \%)$ & 43 (0.30\%) & 4 (0.03\%) & $9(0.06 \%)$ & $14(0.10 \%)$ \\
\hline
\end{tabular}

Each value is a mean of triplicate determination. NOTE: $+=$ positive, $-=$ negative.

Note: CMFMK=Cow milk fermented with kindirmo, CMFMN=Cow milk fermented with Nagge, CMFCO=Cow milk fermented with commercial starter culture, CSMFMK=Cow-soymilk fermented with kindirmo, CSMFMN=Cow-soymilk fermented with Nagge, CSMFCO=Cow-soymilk fermented with commercial starter culture, WSMFMCO=whole soymilk fermented with commercial starter culture. 1, 2, 3 = day I, II, and III respectively.

Table 7 showed $\mathrm{pH}$, titrable acidity and total plate count of yoghurts of the second phase. At day I the pH values ranged from $4.20-6.90$, day II from $3.30-5.30$, day III from $3.40-5.00$ and these correspond to titrable acidity of $0.04-0.09 \%, 0.05-1.09 \%, 0.05-1.09 \%$ and also total plate count from $0.2 \times 10^{5}-36.9 \times 10^{5} \mathrm{cfu} / \mathrm{ml}$, 
Table 6. Sensory scores of yoghurt of the first phase

\begin{tabular}{|c|c|c|c|c|c|c|}
\hline \multirow[t]{2}{*}{ Sample Code } & \multicolumn{6}{|c|}{ Sensory factors } \\
\hline & Consistency & Flavour & Taste & Colour & Texture & Overall acceptance \\
\hline $\mathrm{CMFMK}_{1}$ & $7.60 \pm 2.01^{a-b}$ & $7.90 \pm 1.10^{\mathrm{ab}}$ & $7.60 \pm 1.43^{\mathrm{abc}}$ & $8.10 \pm 0.32^{\mathrm{abc}}$ & $8.40 \pm 0.52^{\mathrm{ab}}$ & $8.10 \pm 0.32^{a b c}$ \\
\hline $\mathrm{CMFMN}_{1}$ & $4.80 \pm 3.82^{a-j}$ & $6.40 \pm 3.24^{\mathrm{ab}}$ & $6.60 \pm 2.95^{a-g}$ & $7.40 \pm 2.22^{\mathrm{a}-\mathrm{e}}$ & $8.20 \pm 1.23^{\mathrm{a}-\mathrm{d}}$ & $6.40 \pm 3.31^{a-f}$ \\
\hline $\mathrm{CMFMC}_{01}$ & $9.00 \pm 0.00^{\mathrm{a}}$ & $8.90 \pm 0.32^{\mathrm{ab}}$ & $9.00 \pm 0.00^{\mathrm{a}}$ & $8.90 \pm 0.32^{\mathrm{a}}$ & $9.00 \pm 0.00^{\mathrm{a}}$ & $8.90 \pm 0.32^{a}$ \\
\hline CSMFMK $_{1}$ & $4.00 \pm 3.43^{\mathrm{c}-\mathrm{j}}$ & $3.40 \pm 2.88^{\mathrm{b}}$ & $3.80 \pm 2.82^{c-j}$ & $5.00 \pm 2.00^{\mathrm{a}-\mathrm{k}}$ & $2.30 \pm 2.06^{\mathrm{k}-\mathrm{g}}$ & $3.00 \pm 2.26^{\mathrm{f}-\mathrm{k}}$ \\
\hline CSMFMN $_{1}$ & $4.10 \pm 2.74^{\mathrm{C}-\mathrm{j}}$ & $2.90 \pm 2.33^{\mathrm{b}}$ & $3.60 \pm 1.84^{\mathrm{d}-\mathrm{j}}$ & $3.80 \pm 2.82^{\mathrm{d}-\mathrm{k}}$ & $3.60 \pm 2.02^{b-k}$ & $3.50 \pm 2.17^{\mathrm{f}-\mathrm{k}}$ \\
\hline CSMFMC $_{01}$ & $3.40 \pm 2.22^{\mathrm{d}-\mathrm{j}}$ & $3.70 \pm 1.70^{\mathrm{b}}$ & $3.80 \pm 2.53^{\mathrm{c}-\mathrm{j}}$ & $3.80 \pm 2.10^{\mathrm{d}-\mathrm{k}}$ & $4.10 \pm 2.02^{\mathrm{b}-\mathrm{k}}$ & $3.80 \pm 2.10^{\mathrm{d}-\mathrm{k}}$ \\
\hline WSMFMC $_{01}$ & $1.10 \pm 0.32^{j}$ & $1.60 \pm 1.26^{\mathrm{b}}$ & $1.30 \pm 0.48^{\mathrm{ij}}$ & $1.50 \pm 1.27^{\mathrm{jk}}$ & $1.40 \pm 0.52^{\mathrm{jk}}$ & $1.90 \pm 2.51^{\mathrm{h}-\mathrm{k}}$ \\
\hline $\mathrm{CMFMK}_{2}$ & $6.20 \pm 2.53^{\mathrm{a}-\mathrm{g}}$ & $6.60 \pm 2.63^{b}$ & $7.60 \pm 1.43^{\mathrm{abc}}$ & $7.40 \pm 1.71^{\mathrm{a}-\mathrm{e}}$ & $6.20 \pm 2.10^{\mathrm{a}-\mathrm{i}}$ & $6.50 \pm 1.58^{\mathrm{a}-\mathrm{t}}$ \\
\hline $\mathrm{CMFMN}_{2}$ & $7.10 \pm 2.33^{\mathrm{a}-\mathrm{e}}$ & $8.00 \pm 1.15^{\mathrm{ab}}$ & $7.50 \pm 1.35^{a-d}$ & $7.50 \pm 1.78^{\mathrm{a}-\mathrm{e}}$ & $7.30 \pm 2.16^{\mathrm{a}-\mathrm{e}}$ & $7.70 \pm 1.49^{\mathrm{a}-\mathrm{e}}$ \\
\hline $\mathrm{CMFMC}_{02}$ & $8.00 \pm 1.15^{\mathrm{abc}}$ & $8.30 \pm 0.48^{\mathrm{ab}}$ & $7.00 \pm 2.67^{a-t}$ & $7.80 \pm 1.55^{\mathrm{a}-\mathrm{e}}$ & $8.30 \pm 1.25^{\mathrm{abc}}$ & $7.80 \pm 2.10^{\mathrm{a}-\mathrm{d}}$ \\
\hline $\mathrm{CSMFMK}_{2}$ & $4.50 \pm 3.21^{\mathrm{b}-\mathrm{j}}$ & $3.50 \pm 2.80^{\mathrm{b}}$ & $2.70 \pm 1.64^{g-j}$ & $4.50 \pm 3.21^{b-k}$ & $3.60 \pm 2.32^{b-k}$ & $4.90 \pm 2.96^{a-k}$ \\
\hline $\mathrm{CSMFMN}_{2}$ & $5.20 \pm 3.21^{\mathrm{b}-\mathrm{j}}$ & $4.20 \pm 2.90^{\mathrm{b}}$ & $4.20 \pm 2.62^{b-j}$ & $5.40 \pm 3.06^{a-k}$ & $4.50 \pm 3.21^{a-k}$ & $5.70 \pm 3.40^{\mathrm{a}-\mathrm{i}}$ \\
\hline CSMFMC $_{02}$ & $5.40 \pm 2.76^{\mathrm{a}-\mathrm{j}}$ & $3.90 \pm 2.28^{b}$ & $3.20 \pm 2.78^{\mathrm{f}-\mathrm{j}}$ & $5.00 \pm 3.20^{a-k}$ & $3.30 \pm 2.63^{\mathrm{d}-\mathrm{k}}$ & $4.10 \pm 3.31^{\mathrm{b}-\mathrm{k}}$ \\
\hline WSMFMC $_{02}$ & $1.40 \pm 0.52^{\mathrm{hij}}$ & $2.60 \pm 2.88^{\mathrm{b}}$ & $2.00 \pm 1.63^{\mathrm{ij}}$ & $1.40 \pm 0.52^{k}$ & $1.10 \pm 0.32^{\mathrm{k}}$ & $1.90 \pm 1.66^{\mathrm{h}-\mathrm{k}}$ \\
\hline $\mathrm{CMFMK}_{3}$ & $7.20 \pm 2.10^{\mathrm{a}-\mathrm{e}}$ & $5.6 \pm 2.67^{b}$ & $4.30 \pm 2.87^{b-j}$ & $6.80 \pm 2.10^{a-g}$ & $6.80 \pm 2.10^{a-g}$ & $5.60 \pm 3.03^{a-i}$ \\
\hline $\mathrm{CMFMN}_{3}$ & $4.40 \pm 3.31^{\mathrm{b}-\mathrm{j}}$ & $2.70 \pm 2.16^{b}$ & $4.30 \pm 2.50^{\mathrm{b}-\mathrm{j}}$ & $4.60 \pm 3.10^{b-k}$ & $4.90 \pm 2.96^{\mathrm{b}-\mathrm{m}}$ & $4.00 \pm 2.58^{\mathrm{c}-\mathrm{k}}$ \\
\hline $\mathrm{CMFMC}_{03}$ & $8.60 \pm 0.52^{\mathrm{ab}}$ & $8.5 \pm 0.53^{a b}$ & $7.30 \pm 2.50^{\mathrm{a}-\mathrm{e}}$ & $8.90 \pm 0.32^{\mathrm{a}}$ & $8.30 \pm 0.48^{\mathrm{abc}}$ & $8.20 \pm 1.23^{\mathrm{ab}}$ \\
\hline $\mathrm{CSMFMK}_{3}$ & $3.50 \pm 3.06^{\mathrm{d}-\mathrm{j}}$ & $3.40 \pm 2.88^{b}$ & $3.40 \pm 2.50^{\mathrm{e}-\mathrm{j}}$ & $3.70 \pm 2.54^{\mathrm{d}-\mathrm{k}}$ & $2.80 \pm 2.39^{e-k}$ & $3.20 \pm 1.23^{\mathrm{ab}}$ \\
\hline $\mathrm{CSMFMN}_{3}$ & $2.80 \pm 3.01^{e-j}$ & $1.30 \pm 0.48^{\mathrm{b}}$ & $1.50 \pm 1.27^{\mathrm{ij}}$ & $3.10 \pm 3.11^{\mathrm{f}-\mathrm{k}}$ & $1.80 \pm 1.23^{\mathrm{ijk}}$ & $2.00 \pm 1.63^{g-k}$ \\
\hline $\mathrm{CSMFMC}_{03}$ & $1.20 \pm 0.42$ & $2.20 \pm 2.39^{b}$ & $1.40 \pm 0.52^{\mathrm{ij}}$ & $1.90 \pm 1.66^{\mathrm{ljk}}$ & $1.30 \pm 0.48^{\mathrm{jk}}$ & $1.10 \pm 0.32^{\mathrm{k}}$ \\
\hline WSMFMC $_{03}$ & $1.40 \pm 1.26^{\text {hij }}$ & $2.30 \pm 1.89^{b}$ & $1.60 \pm 1.26^{\mathrm{ij}}$ & $1.90 \pm 1.66^{\mathrm{ijk}}$ & $2.00 \pm 1.63^{h-k}$ & $1.60 \pm 1.26^{\mathrm{ijk}}$ \\
\hline
\end{tabular}

Each Value is a mean sensory score of ten panellists. Mean values in a column not sharing a common superscript letters are significantly $(p<0.05)$ different. Superscript letters more than three were summarized into range.

Note: CMFMK=Cow milk fermented with kindirmo, CMFMN=Cow milk fermented with Nagge, CMFCO=Cow milk fermented with commercial starter culture, CSMFMK=Cow-soymilk fermented with kindirmo, CSMFMN=Cow-soymilk fermented with Nagge, CSMFCO=Cow-soymilk fermented with commercial starter culture, WSMFMCO=whole soymilk fermented with commercial starter culture. 1, 2, 3 = day I, II, and III respectively.

Table 7. $\mathrm{pH}$, titrable acidity and total plate counts of yoghurt of the second phase

\begin{tabular}{|c|c|c|c|c|}
\hline Sample code & $\mathrm{pH}$ & Titrable acidity (\%) & $\begin{array}{l}\begin{array}{l}\text { Total plate } \\
(\mathrm{CFU} / \mathrm{ml})\end{array} \\
\end{array}$ & count \\
\hline $\mathrm{CMFSK}_{1}$ & $6.90 \pm 0.10^{\mathrm{a}}$ & $0.04 \pm 0.00^{\mathrm{d}}$ & $6.9 \times 10^{5}$ & \\
\hline $\mathrm{CMFSN}_{1}$ & $5.70 \pm 0.10^{d}$ & $0.05 \pm 0.00^{\mathrm{d}}$ & $17.6 \times 10^{5}$ & \\
\hline $\mathrm{CMFSCO}_{1}$ & $5.90 \pm 0.00^{c}$ & $0.04 \pm 0.01^{d}$ & $7.6 \times 10^{5}$ & \\
\hline $\mathrm{CSMFSK}_{1}$ & $5.90 \pm 0.00^{c}$ & $0.04 \pm 0.01^{\mathrm{d}}$ & $3.3 \times 10^{5}$ & \\
\hline $\mathrm{CSMFSN}_{1}$ & $5.7 \pm 0.00^{d}$ & $0.05 \pm 0.01^{d}$ & $1.2 \times 10^{5}$ & \\
\hline $\mathrm{CSMFSCO}_{1}$ & $5.3 \pm 0.00^{\mathrm{e}}$ & $0.05 \pm 0.01^{d}$ & $7.7 \times 10^{5}$ & \\
\hline WSMFSMCO $_{1}$ & $5.90 \pm 0.00^{c}$ & $0.05 \pm 0.01^{d}$ & $10.1 \times 10^{5}$ & \\
\hline $\mathrm{CMFSK}_{2}$ & $3.30 \pm 0.00^{\mathrm{s}}$ & $0.17 \pm 0.00^{\mathrm{b}}$ & $36.1 \times 10^{5}$ & \\
\hline $\mathrm{CMFSN}_{2}$ & $5.10 \pm 0.00^{\text {tg }}$ & $0.05 \pm 0.00^{d}$ & $1.6 \times 10^{5}$ & \\
\hline $\mathrm{CMFSCO}_{2}$ & $4.70 \pm 0.00^{\mathrm{jk}}$ & $0.09 \pm 0.01^{\mathrm{c}}$ & $1.3 \times 10^{5}$ & \\
\hline $\mathrm{CSMFSK}_{2}$ & $4.30 \pm 0.00^{\text {no }}$ & $0.09 \pm 0.01^{\mathrm{c}}$ & $17.0 \times 10^{5}$ & \\
\hline $\mathrm{CSMFSN}_{2}$ & $5.2 \pm 0.00^{\mathrm{ef}}$ & $0.05 \pm 0.00^{d}$ & $1.3 \times 10^{5}$ & \\
\hline $\mathrm{CSMFSCO}_{2}$ & $5.1 \pm 0.00^{\text {tg }}$ & $0.05 \pm 0.00^{d}$ & $13.0 \times 10^{5}$ & \\
\hline WSMFSMCO $_{2}$ & $5.30 \pm 0.00^{\mathrm{e}}$ & $0.05 \pm 0.00^{d}$ & $0.0 \times 10^{5}$ & \\
\hline $\mathrm{CMFSK}_{3}$ & $3.40 \pm 0.00^{\mathrm{s}}$ & $0.17 \pm 0.00^{b}$ & $67 \times 10^{5}$ & \\
\hline $\mathrm{CMFSN}_{3}$ & $4.80 \pm 0.10^{j}$ & $0.08 \pm 0.01^{c}$ & $8.3 \times 10^{5}$ & \\
\hline $\mathrm{CMFSCO}_{3}$ & $4.60 \pm 0.00^{\mathrm{kl}}$ & $0.08 \pm 0.01^{\mathrm{c}}$ & $23.4 \times 10^{5}$ & \\
\hline $\mathrm{CSMFSK}_{3}$ & $4.30 \pm 0.00^{\text {no }}$ & $0.09 \pm 0.01^{\mathrm{c}}$ & $10.5 \times 10^{5}$ & \\
\hline $\mathrm{CSMFSN}_{3}$ & $4.1 \pm 0.00^{\mathrm{pq}}$ & $0.09 \pm 0.01^{\mathrm{c}}$ & $21.9 \times 10^{5}$ & \\
\hline $\mathrm{CSMFSCO}_{3}$ & $4.2 \pm 0.00^{\mathrm{op}}$ & $0.09 \pm 0.01^{\mathrm{c}}$ & $11.1 \times 10^{5}$ & \\
\hline $\mathrm{WSMFSMCO}_{3}$ & $4.40 \pm 0.00^{\mathrm{mn}}$ & $0.09 \pm 0.01^{\mathrm{c}}$ & $26.0 \times 10^{5}$ & \\
\hline
\end{tabular}

Each value is a mean $\pm S D$ of triplicate determination. Mean values in a column not sharing a common superscript letters are significantly $(\mathrm{p}<0.05)$ different.

NOTE: CMFMSK=Cow milk fermented with self processed kindirmo, CMFMSN=Cow milk fermented with self processed Nagge, CMFSCO=Cow milk fermented with self processed commercial starter culture, CSMFMSK=Cow-soymilk fermented with self processed kindirmo, CSMFMSN=Cow-soymilk fermented with self processed Nagge, CSMFSCO=Cow-soymilk fermented with self processed commercial starter culture, WSMFMSCO=whole soymilk fermented with self processed commercial starter culture. 1, 2, $3=$ day I, II, and III respectively. 
114 Afr. J. Food Sci. Technol.

Table 8. Distribution of microorganisms in yoghurt of the second phase

\begin{tabular}{|c|c|c|c|c|c|c|c|}
\hline Samples Code & Streptococcus sp & Micrococcus sp & Bacillus $s p$ & Lactobacillus $s p$ & $\begin{array}{l}\text { Staphylococcus } \\
\text { aureus }\end{array}$ & Yeast cell & Mucor sp \\
\hline $\mathrm{CMFSK}_{1}$ & $+(65)$ & $+(4)$ & $-(0)$ & $-(0)$ & $-(0)$ & $-(0)$ & $-(0)$ \\
\hline $\mathrm{CMFSN}_{1}$ & $+(145)$ & $+(31)$ & - & $-(0)$ & $-(0)$ & $-(0)$ & $-(0)$ \\
\hline $\mathrm{CMFSCO}_{1}$ & $+(70)$ & $+(3)$ & $-(0)$ & $+(3)$ & $-(0)$ & $-(0)$ & $-(0)$ \\
\hline CSMFSK $_{1}$ & $+(29)$ & $+(4)$ & $-(0)$ & $-(0)$ & $-(0)$ & $-(0)$ & $-(0)$ \\
\hline $\mathrm{CSMFSN}_{1}$ & $+(11)$ & $+(1)$ & $-(0)$ & $-(0)$ & $-(0)$ & $-(0)$ & $-(0)$ \\
\hline $\mathrm{CSMFSCO}_{1}$ & $+(70)$ & $+(7)$ & $-(0)$ & $-(0)$ & $-(0)$ & $-(0)$ & $-(0)$ \\
\hline WSMFSCO$_{1}$ & $+(85)$ & $+(16)$ & $-(0)$ & $-(0)$ & $-(0)$ & $-(0)$ & $-(0)$ \\
\hline $\mathrm{CMFSK}_{2}$ & $+(331)$ & $+(30)$ & $-(0)$ & $-(0)$ & $-(0)$ & $-(0)$ & $-(0)$ \\
\hline $\mathrm{CMFSN}_{2}$ & $+(14)$ & $+(2)$ & $-(0)$ & $-(0)$ & $-(0)$ & $-(0)$ & $-(0)$ \\
\hline $\mathrm{CMFSCO}_{2}$ & $+(9)$ & $+(1)$ & $+(1)$ & $+(1)$ & $-(0)$ & $-(0)$ & $+(2)$ \\
\hline $\mathrm{CSMFSK}_{2}$ & $+(156)$ & $+(10)$ & $-(0)$ & $-(0)$ & $-(0)$ & $-(0)$ & $+(4)$ \\
\hline $\mathrm{CSMFSN}_{2}$ & $+(8)$ & $+(2)$ & $-(0)$ & $-(0)$ & $-(0)$ & $+(2)$ & $+(1)$ \\
\hline $\mathrm{CSMFSCO}_{2}$ & $+(112)$ & $+(16)$ & - & $-(0)$ & - & $-(0)$ & $+(2)$ \\
\hline WSMFSCO $_{2}$ & $+(0)$ & $+(0)$ & $-(0)$ & $-(0)$ & $-(0)$ & $-(0)$ & $-(0)$ \\
\hline $\mathrm{CMFSK}_{3}$ & $+(55)$ & $+(12)$ & - & $-(0)$ & - & - & $-(0)$ \\
\hline $\mathrm{CMFSN}_{3}$ & $+(70)$ & $+(13)$ & $-(0)$ & $-(0)$ & $-(0)$ & $-(0)$ & $-(0)$ \\
\hline $\mathrm{CMFSCO}_{3}$ & $+(188)$ & $+(42)$ & $+(2)$ & $+(2)$ & $-(0)$ & $-(0)$ & $+(2)$ \\
\hline $\mathrm{CSMFSK}_{3}$ & $+(87)$ & $+(15)$ & $-(0)$ & $-(0)$ & $-(0)$ & $-(0)$ & $+(3)$ \\
\hline $\mathrm{CSMFSN}_{3}$ & $+(195)$ & $+(18)$ & $-(0)$ & $-(0)$ & $-(0)$ & $+(2)$ & $+(4)$ \\
\hline $\mathrm{CSMFSCO}_{3}$ & $+(77)$ & $+(29)$ & $-(0)$ & $-(0)$ & $-(0)$ & $-(0)$ & $+(5)$ \\
\hline $\mathrm{WSMFSCO}_{3}$ & $+(246)$ & $+(11)$ & - & $-(0)$ & $-(0)$ & $+(1)$ & $+(2)$ \\
\hline $\begin{array}{l}\text { TOTAL } \\
\text { PERCENAGE }\end{array}$ & 2023 (86.86\%) & 267 (11.46\%) & $3(0.13 \%)$ & $6(0.26 \%)$ & $0(0.00 \%)$ & $5(0.22 \%)$ & $\begin{array}{l}25 \\
(1.07 \%)\end{array}$ \\
\hline
\end{tabular}

Each value is a mean of triplicate determination.

NOTE: CMFMSK=Cow milk fermented with self processed kindirmo, CMFMSN=Cow milk fermented with self processed Nagge, CMFSCO=Cow milk fermented with self processed commercial starter culture, CSMFMSK=Cow-soymilk fermented with self processed kindirmo, CSMFMSN=Cow-soymilk fermented with self processed Nagge, CSMFSCO=Cow-soymilk fermented with self processed commercial starter culture, WSMFMSCO=whole soymilk fermented with self processed commercial starter culture. 1, 2, 3 = day I, II, and III respectively.

Table 9. Sensory scores of yoghurts of the second phase

\begin{tabular}{|c|c|c|c|c|c|c|}
\hline Sample Code & Sensory factors & & & & & \\
\hline & Consistency & Flavour & Taste & Colour & Texture & $\begin{array}{l}\text { Overall } \\
\text { acceptance }\end{array}$ \\
\hline $\mathrm{CMFSK}_{1}$ & $5.80 \pm 2.97^{a-h}$ & $6.20 \pm 2.82^{\mathrm{b}}$ & $6.40 \pm 2.50^{a-h}$ & $6.70 \pm 2.98^{a-g}$ & $5.70 \pm 3.31^{a-k}$ & $5.40 \pm 2.37^{\mathrm{a}-\mathrm{j}}$ \\
\hline $\mathrm{CMFSN}_{1}$ & $5.90 \pm 2.85^{\mathrm{a}-9}$ & $7.00 \pm 2.67^{\mathrm{ab}}$ & $7.00 \pm 1.76^{\mathrm{a}-\mathrm{f}}$ & $8.30 \pm 0.48^{\mathrm{ab}}$ & $7.30 \pm 2.00^{\mathrm{ab}}$ & $6.10 \pm 3.28^{a-g}$ \\
\hline $\mathrm{CMFSC}_{01}$ & $6.90 \pm 2.47^{\mathrm{a}-\mathrm{e}}$ & $7.60 \pm 2.01^{\mathrm{ab}}$ & $7.80 \pm 2.39^{\mathrm{ab}}$ & $7.90 \pm 2.42^{\mathrm{a}-\mathrm{d}}$ & $7.20 \pm 2.78^{a-f}$ & $6.80 \pm 2.39^{a-f}$ \\
\hline CSMFSK1 & $5.70 \pm 3.13^{a-i}$ & $3.80 \pm 2.79^{\mathrm{b}}$ & $4.60 \pm 2.37^{\mathrm{b}-\mathrm{j}}$ & $5.40 \pm 2.76^{a-k}$ & $3.40 \pm 1.71^{\mathrm{d}-\mathrm{k}}$ & $5.40 \pm 3.27^{\mathrm{a}-\mathrm{j}}$ \\
\hline $\mathrm{CSMFSN}_{1}$ & $6.40 \pm 3.31^{a-f}$ & $3.90 \pm 2.96^{\mathrm{b}}$ & $4.60 \pm 3.60^{b-j}$ & $4.70 \pm 2.98^{a-k}$ & $3.50 \pm 2.18^{\mathrm{d}-\mathrm{k}}$ & $4.70 \pm 2.91^{\mathrm{b}-\mathrm{k}}$ \\
\hline CSMFSC $_{01}$ & $6.10 \pm 3.31^{a-g}$ & $3.90 \pm 2.69^{\mathrm{b}}$ & $4.00 \pm 2.58^{\mathrm{b}-\mathrm{j}}$ & $5.70 \pm 2.50^{\mathrm{a}-\mathrm{j}}$ & $3.10 \pm 2.18^{\mathrm{d}-\mathrm{k}}$ & $4.70 .2 .91^{\mathrm{b}-\mathrm{k}}$ \\
\hline WSMFSC $_{01}$ & $2.90 \pm 3.00^{e-j}$ & $2.90 \pm 1.85^{\mathrm{b}}$ & $2.10 \pm 2.47^{i j}$ & $2.30 \pm 2.36^{h-k}$ & $1.80 \pm 1.23^{\mathrm{ijk}}$ & $1.40 \pm 0.52^{\mathrm{jk}}$ \\
\hline $\mathrm{CMFSK}_{2}$ & $5.30 \pm 2.91^{\mathrm{a}-\mathrm{j}}$ & $3.70 \pm 2.63^{\mathrm{b}}$ & $4.90 \pm 3.21^{\mathrm{b}-1}$ & $5.40 \pm 2.67^{a-k}$ & $5.30 \pm 2.54^{a-1}$ & $6.20 \pm 2.78^{a-t}$ \\
\hline $\mathrm{CMFSN}_{2}$ & $7.40 \pm 1.71^{a-d}$ & $6.50 \pm 3.06^{\mathrm{b}}$ & $7.50 \pm 1.35^{a-d}$ & $6.40 \pm 2.32^{\mathrm{a}-\mathrm{h}}$ & $6.0 \pm 2.16^{a-j}$ & $7.70 \pm 1.49^{\mathrm{a}-\mathrm{e}}$ \\
\hline $\mathrm{CMFSC}_{02}$ & $7.50 \pm 2.32^{a-d}$ & $7.90 \pm 1.60^{\mathrm{ab}}$ & $7.70 \pm 1.49^{\mathrm{abc}}$ & $7.30 \pm 2.16^{a-f}$ & $6.50 \pm 2.46^{a-h}$ & $7.00 \pm 2.26^{a-f}$ \\
\hline $\mathrm{CSMFSK}_{2}$ & $1.40 \pm 0.52^{\mathrm{hij}}$ & $2.30 \pm 1.06^{\mathrm{b}}$ & $2.50 \pm 1.78^{\mathrm{hij}}$ & $4.00 \pm 3.20^{c-k}$ & $4.50 \pm 2.88^{a-k}$ & $3.60 \pm 2.32^{e-k}$ \\
\hline $\mathrm{CSMFSN}_{2}$ & $3.60 \pm 2.32^{c-j}$ & $3.50 \pm 2.80^{\mathrm{b}}$ & $3.60 \pm 2.32^{\mathrm{d}-\mathrm{j}}$ & $6.00 \pm 3.50^{a-i}$ & $4.20 \pm 2.62^{b-k}$ & $4.80 \pm 2.74^{a-k}$ \\
\hline CSMFSC $_{02}$ & $2.30 \pm 2.06^{\mathrm{f}-\mathrm{j}}$ & $2.50 \pm 1.78^{\mathrm{b}}$ & $3.90 \pm 2.69^{\mathrm{b}-\mathrm{j}}$ & $5.30 \pm 3.53^{\mathrm{a}-\mathrm{k}}$ & $5.50 \pm 2.92^{\mathrm{a}-1}$ & $4.60 \pm 1.90^{\mathrm{b}-\mathrm{k}}$ \\
\hline WSMFSC $_{02}$ & $1.30 \pm 0.48^{j i}$ & $1.10 \pm 0.32^{\mathrm{b}}$ & $1.70 \pm 1.25^{\mathrm{ij}}$ & $1.70 \pm 1.25^{\mathrm{jk}}$ & $2.70 \pm 2.00^{\mathrm{f}-\mathrm{k}}$ & $1.40 \pm 0.70^{\mathrm{jk}}$ \\
\hline $\mathrm{CMFSK}_{3}$ & $5.40 \pm 3.34^{a-j}$ & $4.10 \pm 2.73^{\mathrm{b}}$ & $3.00 \pm 2.26^{g-j}$ & $4.80 \pm 3.35^{a-k}$ & $3.10 \pm 2.85^{\mathrm{d}-\mathrm{k}}$ & $4.50 \pm 3.21^{b-k}$ \\
\hline $\mathrm{CMFSN}_{3}$ & $5.40 \pm 3.27^{a-j}$ & $5.50 \pm 3.17^{b}$ & $3.50 \pm 2.80^{e-j}$ & $7.00 \pm 2.52^{\mathrm{a}-\mathrm{f}}$ & $3.60 \pm 2.72^{\mathrm{b}-\mathrm{k}}$ & $6.00 \pm 2.87^{\mathrm{a}-\mathrm{h}}$ \\
\hline $\mathrm{CMFSC}_{03}$ & $7.00 \pm 2.94^{\mathrm{a}-\mathrm{e}}$ & $6.60 \pm 3.44^{\mathrm{b}}$ & $5.20 \pm 2.74^{a-i}$ & $7.80 \pm 2.44^{a-e}$ & $4.60 \pm 2.67^{c-n}$ & $6.40 \pm 3.00^{\mathrm{a}-\mathrm{f}}$ \\
\hline $\mathrm{CSMFSK}_{3}$ & $4.70 \pm 2.91^{\mathrm{a}-\mathrm{J}}$ & $4.30 \pm 3.09^{b}$ & $2.40 \pm 2.32^{11}$ & $3.90 \pm 2.28^{c-k}$ & $1.80 \pm 2.20^{\mathrm{jk}}$ & $3.10 \pm 2.85^{t-k}$ \\
\hline $\mathrm{CSMFSN}_{3}$ & $4.90 \pm 3.21^{a-j}$ & $4.80 \pm 2.74^{\mathrm{b}}$ & $3.80 \pm 2.78^{c-j}$ & $3.60 \pm 2.72^{e-k}$ & $2.10 \pm 1.60^{n-k}$ & $3.90 \pm 2.69^{\mathrm{d}-\mathrm{k}}$ \\
\hline $\mathrm{CSMFSC}_{03}$ & $6.30 \pm 2.91^{\mathrm{a}-\mathrm{g}}$ & $3.90 \pm 2.96^{\mathrm{b}}$ & $3.10 \pm 2.18^{t-1}$ & $4.00 \pm 2.87^{c-k}$ & $2.70 \pm 2.16^{n-k}$ & $3.90 \pm 2.90^{\mathrm{b}-\mathrm{k}}$ \\
\hline WSMFSC $_{03}$ & $1.90 \pm 2.18^{g-j}$ & $1.10 \pm 0.32^{\mathrm{b}}$ & $1.10 \pm 0.32^{\mathrm{j}}$ & $2.60 \pm 2.50^{g-k}$ & $1.10 \pm 0.32^{\mathrm{k}}$ & $1.10 \pm 0.32^{k}$ \\
\hline
\end{tabular}

Each Value is a mean sensory score of ten panellists. Mean values in a column not sharing a common superscript letters are significantly $(p<0.05)$ different. Superscript letters more than three were summarized into range.

NOTE: CMFMSK=Cow milk fermented with self processed kindirmo, CMFMSN=Cow milk fermented with self processed Nagge, CMFSCO=Cow milk fermented with self processed commercial starter culture, CSMFMSK=Cow-soymilk fermented with self processed kindirmo, CSMFMSN=Cow-soymilk fermented with self processed Nagge, CSMFSCO=Cow-soymilk fermented with self processed commercial starter culture, WSMFMSCO=whole soymilk fermented with self processed commercial starter culture. 1, 2, 3 = day I, II, and III respectively. 
$0.0 \times 10^{5}-36.1 \times 10^{5}$ and $2.7 \times 10^{5}-51.76 \times 10^{6} \mathrm{cfu} / \mathrm{ml}$ respectively.Table 8 showed the distribution of microorga nisms in yoghurts of the second phase. Microorganisms isolated are Streptococcus sp 2,023 (86.86\%), Micrococcus sp 267 (11.46\%), Lactobacillus sp 6 (0.30\%), Bacillus sp 3 (0.13\%), Mucor sp 25 (1.07\%) and un-identified group of yeast cells $5(0.06 \%)$. Day III also has the highest percentage microorganisms. All percentage of microorganisms decreases except Mucor $s p$ which were increased. Staphylococcus $s p$ were not observed as in the first phase of yogurts. Yeasts and Mucor $s p$ were also observed at day II and III and were found mostly associated with yoghurts produced from cow-soymilk (1:1) and soymilk (100\%). Streptococcus sp and Micrococcus $s p$ were found to dominate groups of yoghurts produced.

Table 9 showed sensory scores of yoghurts of the second phase. Similar pattern was observed as stated in Table 6. However, yoghurts of the second phase were rated much lower than the first phase.

\section{DISCUSSION}

There are many changes occurred during these periods of study. These changes are in $\mathrm{pH}$, titrable acidity, total plate count and microbial distribution. Irregular patterns of changes were observed though in few cases. These may be attributed to spoilage (Ray, 2001). At day I, the $\mathrm{pH}$ and titrable acidity of the milks are remarkable and correspond to the $\mathrm{pH}$ value of fresh milk as $6.4-6.7$, titrable acidity as $0.14-0.18 \%$ (Ihekoronye and Ngoddy, 1985; Egan et al., 1988; Olorunnisomo et al., 2014). Also Udeozor (2012) and Bristone et al. (2015) reported in their research work on fresh cow milk and soymilk. Their work has values corresponded with the values obtained. The total plate count of day I also correspond to the values reported by Olorunnisomo et al. (2014). Also pasteurized fresh milks were found to have a total plate count with variation and up to $2.62 \times 10^{2} \mathrm{cfu} / \mathrm{ml}$ (Udeozor and Awonorin, $2014{ }^{)}$. Similar study was also reported by Wakil et al. (2014). It is interesting to know that between $0.4-0.6 \%$ acidity, milk began to taste sour and by the time it reaches $0.6 \%$ acidity at ordinary temperature, it curdles. At that time different spoilage pattern was reported to set up in heat treated milk due to changes in microbial flora (Egan et al., 1988). This was reflected at day II of this study in Table 1 . The total plate count of day I may indicate heat resistant organisms (Pelczar, 1993; Adams and Moss, 1999).

Microorganisms are well known to associate with milk because of its nutritional values. The types of microorganisms reported in fresh milk are usually Micrococcus sp, Streptococcus sp, Deptheroid corynebacteriumbovis, member of the genera of Mycob acteria, Enterococcus Lactobacillus (Pelczar, 1993; Adams and Moss,1999). However, only Micrococcus $s p$,
Streptococcus sp, and Yeast were encountered. These three isolates are typical spoilage organisms. They were reported to have no significant negative health implication in food except some few number of Yeast (Pelczar, 1993; Ihekoronye and Ngoddy, 1985; Adams and Moss, 1999; Ray, 2001; Jideani and Jideani, 2006). Spoilage of milk was known to be predominantly caused by the gramnegative Psychrotrophic rods such as Pseudomonas, Alcaligenes, Flavobacterium $s p$ and some Coliforms (Ray, 2001). This indicated safe nature of these pasteurized milks even after spoilage or fermentation as observed at day II.

Sensory attribute of fresh cow and soymilk (day I) were much comparable in terms of their sensory attributes. These mean that fresh soymilk can be substituted for cow milk drinks. Sowonola et al. (2005), Udeozor (2012) and Adedokun et al. (2014) evaluated sensory attributes of milks from plants sources results were much acceptable. Bristone et al. (2015) also evaluated sensory attributes of tiger nut milk, soymilk and compared with cow milk. Results of this investigation were awesome in terms of level of acceptability. Therefore, researchers have already attended goal of producing milk from plants sources much comparable with cow milk in terms of sensory attributes. However, cow milk of day II was better than the soymilk. This indicated variation upon incubation.

The $\mathrm{pH}$ and titrable acidity of fresh yoghurts were generally reported to vary, but usually ranged between $3.8-5.11$ and $0.85-0.95 \%$ respectively (Egan et al., 1988; Stringer, 2000; Ray, 2001; Igbadul et al., 2014, Olorunnisomo et al., 2014). It can be observed that most of yoghurts produced are within this range of values. However, upon fermentation of the yoghurts there was an increase in titrable acidity as high as $1.09 \%$. These occurred in cow milk fermented with indigenous starter culture and also cow milk fermented with Nagge yoghurt of day II and III. Such level of titrable acidity was also noted by El - batawy et al. (2014), Olorunnisomo et al. (2014) and Bristone et al. (2015). Lactobacillus acidophilus, Lactobacillus casei and Bifidobacterium sp were known to give mellow fruity and acid flavours (Stringer, 2000). Recession in $\mathrm{pH}$ of two yoghurt samples was also observed and this was also noted from Olorunnisomo et al. (2014). These type of changes may be due to production of bitter peptides by some strain of Lactobacillus delbrueckii sub sp, bulgaricus (Ray, 2001). There was also an increase in microbial load upon fermentation up to $90.7 \times 10^{5} \mathrm{cfu} / \mathrm{ml}$. Microbial counts from various yoghurt samples as reported by many researchers were not far from these observed values (Farinde et al., 2008; Pham and Shah, 2009; Olorunnisomo et al., 2014; Bibiana et al., 2014; Bristone et al., 2015).

In this study, low level of Lactobacillus $s p$ in the various yoghurts is probably due to low temperature incubation below optimum growth condition (Frazier, 
1986). Staphylococcus aureus is of significant concern due to its health implication (Frazier, 1986; Pelczar, 1993; Jideani and Jideani, 2006). However, its presence was not encountered at day II and III examination. Probably because of the low $\mathrm{pH}$ level and presence of bacteriocin producing bacteria (Ray, 2001, Shannawaz et al., 2013). Similar study conducted by Farinde et al. (2008) encountered Staphylococcus aureus in fresh yoghurts. Bacillus sp are much more important under anaerobic condition. However, there are some species known to cause food infection especially in children (Frazier, 1986; Jideani and Jideani, 2006). Presence of Yeast and Mucor $\mathrm{sp}$ may indicate final stage of yoghurt spoilage (Ray, 2001). Highest percentage microorganisms were observed at day III. This study indicated health safety in yoghurt even after spoilage, since organisms of much concern were not encountered at critical incubation period.

One of the characteristics of good yoghurt is the sensory attributes. Most of the sensory attributes of yoghurts related soybeans falls below established base line statistics of liked and disliked (5). Similar studies using plants as sources of milk indicated corresponding values (Akoma et al., 2000; Farinde et al., 2008; Amanze and Amanze, 2011; Bristone et al., 2014). However, there was much improvement of the yoghurt composites of day II. One can therefore said that biotransformation of isoflavone glycosides to biologically active forms in soymilk would also depend on specific fermentation time for acceptable sensory attributes.

In yoghurt of the second phase, the difference is that the $\mathrm{pH}$ is from $3.30-6.9$, titrable acidity from $0.04-0.17$ and total plate count from $0.0 \times 10^{5}-36.1 \times 10^{5} \mathrm{cfu} / \mathrm{ml}$. There was only one sample of yoghurt that recession in $\mathrm{pH}$ was observed. There was also slight fluctuation and low microbial load observed in some yoghurts samples and this might have been one of the reasons in low rating of yoghurts. Results of this investigation were as reported by many researchers (Egan et al., 1988; Stringer, 2000; Ray, 2001; Igbadul et al., 2014, Olorunnisomo et al., 2014). High total plate count mostly observed at day II and III. This indicated high microbial activity at those stages.

In this second phase of yoghurts all the percentages microorganism encountered in the first phase significantly decreased. However, percentage of Mucor $\mathrm{sp}$ was increased and there was no indication of Staphylococcus aureus as observed in the first phase. Day III of this study has the highest percentage microorganisms. Microbial findings were as described by many researchers in similar studies (Farinde et al., 2008; Pham and Shah, 2009; Olorunnisomo et al., 2014; Bibiana et al., 2014; Bristone et al., 2015).

Generally, acceptability of yoghurt samples decreases as observed upon fermentation. However, similar study under very low temperature indicated more acceptability of yoghurts (Olorunnisomo et al., 2014). The sensory scores of yoghurts irrespective of starter culture were rated lower than the yoghurt of the first phase. On the other hand, the soymilk yoghurts and its composites were still comparable to many researchers work (Akoma et al., 2001; Farinde et al., 2008; Amanze and Amanze, 2011; Bristone et al., 2015). However, day I soymilk yoghurts and its composites were more acceptable than their subsequent counterpart of day II and III.

\section{CONCLUSIONS}

The research work covered microbial ecology and acceptability of whole cow milk, whole soymilk and yoghurts produced from them using different starter cultures (Kindirmo, Fresh Nagge, Commercial starter culture). Cow milks yoghurt obtained from these three starter cultures were further processed and used as cultures (self-processed starter cultures). These were used again to inoculate the above milks and their composites ("back-sloping"). Their $\mathrm{pH}$, titrable acidity, microbiological properties and sensory attributes were evaluated.

Results of analysis indicated fresh cow milk and soymilk are much comparable in terms of sensory attributes. However, cow milk yoghurts are much more acceptable than soymilk yoghurt and their composites. Recession in $\mathrm{pH}$ of some yoghurt during fermentation may indicate sign of spoilage. Freshly prepared culture from initial stock culture produced good quality yoghurts. Milk fermentation is a way of increasing the microbial safety of milk as observed.

\section{ACKNOWLEDGEMENT}

The authors are grateful to Alhaji Baba Shedi Bakalchi for the provision of fresh cow milk and kindirmo. Also to students and lecturers of the Department of Food Science and Technology who were selected as taste panellists.

\section{DECLARATION OF INTEREST}

There was no funding source for this research work. All authors contributed, and all have reviewed the manuscript and approved the final version submitted for publication.

\section{REFERENCES}

Adams MR, Moss MO (1999). Food microbiology, Cambridge: Royal Society of Chem.

Adedokun I I, Okorie SU, Barizaa B (2014). Evaluation of proximate, fibre qualities and consumer acceptability of bambara nut - tiger nut - coconut milk beverage blends. International J. Nutri. and Food Sci. 3(5), 430 - 437.

Akoma O, Elekwa UO, Afodunrinbi AT, Onyeukwu GC (2001). Yoghurt 
from coconut and tiger nut. The J. Food Tech. in Africa, 5(4), 132 - 134.

Akpan U G, Mohammed A D, Aminu I (2007). Effect of preservation on the shelf life of yoghurt produced from soya beans milk. Leonardo Electronic J. Practices and Technologies, 131 - 142.

Amanze KO, Amanze JO (2011). Quality evaluation of yoghurt from cow milk, soymilk and cow / soymilk. JORIND 9 (2): 44 - 47.

Badau MH, Jideani IA, Nkama I (2005). Production, acceptability and microbiological evaluation of weaning food formulations. Journal of Tropical Pediatrics, 52, 162 - 172.

Badau MH, Jideani IA, Nkama I (2006). Rheological behaviour of weaning food formulations as affected by addition of malt. International J. Food Sci. and Tech, 41, 1222 - 1228.

Bamishaiye El, Bamishaiye OM (2011). Tiger nut: as a plant, its derivatives and benefits. African Journal of Food, Agriculture, Nutrition and Development, 11(5), 5157 - 5169.

Blanco JL, Sherbo GH (1978). Standard methods for the examination of dairy products. NWDC American Public Health Association

Bristone C, Badau MH, Igwebuike JU, Igwegbe AO (2015). Production and evaluation of yoghurt from mixtures of cow milk, milk extract from soybeans and tiger nut. World J. Dairy and Food Sci, 10(2), 159 - 169.

Cheesbrough M (2000). District Laboratory Practice in Tropical Countries, part 2. U.S.A: Cambridge University Press.

Diliello Lk (1982).Methods in food and dairy microbiology, Westport Connecticut, USA: AVI publishing company, Inc.

Dubey RC, Maheshwari DK (2014). A textbook of microbiology, Ram Nagar, New Delhi: S. Chand and company PVT. Ltd..

Duncan DE (1955). Multiple range and multiple f-tests, Biometrics.

Egan H, Skirk RS, Sawyer R (1988). Pearson's chemical analysis of food, London: Longman Scientific and Technical.

El - batawy OI, Ashoush IS, Nayra SM (2014): Impact of mango and pomegranate peels supplementation on quality characteristics of yoghurt with or without whey powder. World J. Dairy and Food Sci. $9(1), 57-65$

Farinde EO, Obatola VA, Fasoyiro SB, Adeniran AH, Agboola ER (2008). Use of alternative raw materials for yoghurt production. African J. Biotechnology, 7(18), 3339 - 3345.

Farnworth ER, Mainville I, Desjardins MP, Gardner N, Fliss I, Champagne C (2006).Growth of probiotic bacteria and bifidobacteria in a soy yoghurt formulation. Intel. J. Food Microbiology, 116(2007), 174 - 181.

Fawole $\mathrm{MO}(1988)$. Laboratory manual of microbiology. Ibadan: Spectrum books Ltd.

Frazier WC (1986). Food microbiology. New Delhi: McGraw Hill, Inc.

Gambo A, Da'u A (2014). Tiger nut (cyperus esculentus): composition, products, uses and health benefits $-A$ review. Bayero J. Pure and Applied Sci. 7(1), 56 - 61.

Gomez AK, Gomez AA (1983). Statistical procedures for agricultural research, New York: John Wiley and Sons Itd.

Harrigan WF, McCance ME(1976). Laboratory methods in food and dairy microbiology, San Francisco, New York: Academic Press.

Igbadul B, Shember J, Amove J (2014). Physicochemical, microbiological and sensory evaluation of yoghurt sold in Makurdi metropolis. African J, Food Sci. and Tech. 5(6), 129 - 135.

Ihekoronye Al (1999). Manual on small scale food processing and opportunities, In: mall-scale food processing. Nsukka, Nigeria: Academic published

Ihekoronye Al, Ngoddy PO (1985). Integrated food science and technology for the tropics, London: Macmillan Edu.

Ismael SM, Farahat AM, Ebrahim, Y M, Gohari ST (2014). Functional and nutritional properties of stirred yoghurt supplemented with silymarin and its impact on chronic hepatic damage. World J. Dairy and Food Sci. 9(1), 36 - 50

Iwe MO (2003). The science and technology of soybeans chemistry, nutrition, processing, utilization, Umahia, Nigeria: Rejoint communications services Ltd.

Jideani VA, Jideani IA (2006). Laboratory manual of food bacteriology, Kaduna, Nigeria: Amana Printing and Advertising Ltd.

Larmond E (1977). Laboratory methods for sensory evaluation of food, Ottawa, Canada: Canadian Government Publishing Centre.
Liener IE (1989). Legumes, chemistry, technology and human, New York: Marced Dekker, Inc.

Mullan WMA (2001).Microbiology of starter cultures. Retrieved from: htt ps//www.dairyscience.info/index.php/cheese-starters/49-cheesestarters.html. Accessed: 23 February, 2016.

Musa AA, Hamza A (2013). Comparative analysis of locally prepared "Kununaya" (Tiger nut milk) consumed by students of Kaduna State University, Kaduna, Nigeria. Science World Journal, 8(2), 13 - 18.

Nwobosi PNU, Isu NR, Agarr OO (2013). Influence of pasteurization and use of natural tropical preservatives on the quality attributes of tiger nut drink during storage. Intel. J, Food and Nutri. Science, 2(1), $27-32$.

Odu NN, Egbo NN (2012). Assessment of the effect of different preservatives on the physic - chemical quantity of soymilk stored at different temperatures. Nature and Sci. 10(8), 77 - 84.

Ogbonn AC, Abuajah Cl, Utuk RA (2013). Tiger nut milk: a nutritious underutilized food ingredient. Food Biology, 2(2), 14 - 17.

Okorie SU, Adedokun II, Nwachukwu CN, Ihemeje A (2014). Mineral composition of bambara nut - tiger nut - coconut mil beverage blends. J. Food and Nutri. Sci. 2(5), 231- 235

Olorunnisomo OA, Ososanya TO, Adedeji OY (2014). Homogenization of milk and its effect on sensory and physico-chemical properties of yoghurt. African Journal of Food Science, 8 (9), 465 - 470.

Ory RL (1986). Plant proteins: applications, biological effects and chemistry: Developed from a symposium sponsored by the division of agricultural and food chemistry at the $190^{\text {th }}$ meeting of the American Chemical Society, Illinois, Chicago: ACS Symposium Series 312

Pelcza MJ (1993). Microbiology, New Delhi: Tata McGraw Hill Publishing Company Ltd.

Pham TT, Shah NP (2009). Effects of skim milk powder supplementation to soy yoghurts on biotransformation of isoflavone glyosides to biological active form during storage. Intel . J. Biological and Life Sci. 5(1), 18 - 26.

Prescott LM (1996). Microbiology, New Delhi: McGraw Hill Companies, Inc.

Ray B (2001). Fundamental food microbiology, USA: CRC Press LLC.

Salunke DK, Chavan JC, Adsule RN, Kadam SS (1992). World Oilseeds, Chemistry, Technology and Utilization, Van NostrandReinland, New York: An AV Book Published.

Shahnawaz M, Sheikh SH, Akbar ZA (2013). Physicochemical analysis of desi yoghurts produced by the local community in Gilgit District. African J. Food Sci. 7(7), 183 - 185.

Singleton P (1999). Bacteria in biology, biotechnology and medicine, Chippenham: John Wiley and Sons Ltd

Sowonolo OA, Tunde - Akintunde TY, Adedeji F (2005). Nutritional and sensory qualities of soymilk - kunnu blends. Peer reviewed article. African J. Food and Nutrition Sciences, 5(2), 1 - 12.

Sudi IY, De N, Dunkrah UA (2011). Nigerian indigenous yoghurt (Kindirmo) production using Lactobacillus bulgaricus and Streptococcus thermophilus mutants as starter culture. African J. Biotechnology, 10(9), 1651 - 1654.

Sukumar DE (2002). Outline of dairy technology, New Delhi: Manzar Khan Ltd.

Udeozor LO (2012). Tiger nut - soymilk drink: preparation, proximate composition and sensory qualities. International J. Food and Nutri. Sci. 1(4), 18 - 26.

Udeozor LO Awonorin SO (2014). Comparative microbial analysis and storage of tiger nut soy milk extract. Australian J. Nutri. and Food Sci. 2(5), 1- 6.

Ukwuru MU, Ogbodo AC (2011). Effect of processing treatment on the quality of tiger nut milk. Pakistan J. Nutri. 10(1), 95 - 100.

Wakil SM, Ayenuro OT, Oyinlola KA (2014). Microbiological and nutritional assessment of starter-developed fermented tiger nut milk. Food and Nutri. Sci. 5, 495 - 506.

Yao AA, Dorto C, Egounlety M, Pinto C, Edward VA, Huch M, Franz CMAP, Holzapfel W, Mbugua S, Mengu M, Thonart P (2009).

Production of Ifreeze - dried lactic acid bacteria starter culture for cassava fermentation into gari. African J. Biotechnology, 8(19), 49965004 